\title{
The Effect of Font Size on Reading Performance in Strabismic Amblyopia: An Eye Movement Investigation
}

\author{
Evgenia Kanonidou, Irene Gottlob, and Frank A. Proudlock
}

Ophthalmology Group, University of Leicester, Faculty of Medicine and Biological Sciences, Robert Kilpatrick Clinical Sciences Building, Leicester Royal Infirmary, Leicester, United Kingdom

Correspondence: Frank A. Proudlock, Ophthalmology Group, University of Leicester, Faculty of Medicine and Biological Sciences, Robert Kilpatrick Clinical Sciences Building, Leicester Royal Infirmary, PO Box 65, Leicester LE2 7LX, UK fap1@le.ac.uk

Submitted: September 13, 2013 Accepted: December 9, 2013

Citation: Kanonidou E, Gottlob I, Proudlock FA. The effect of font size on reading performance in strabismic amblyopia: an eye movement investigation. Invest Ophthalmol Vis Sci. 2014;55:451-459. DOI:10.1167/iovs. $13-13257$

\begin{abstract}
Punpose. We investigated the effect of font size on reading speed and ocular motor performance in strabismic amblyopes during text reading under monocular and binocular viewing conditions.
\end{abstract}

Methods. Eye movements were recorded at $250 \mathrm{~Hz}$ using a head-mounted infrared video eye tracker in 15 strabismic amblyopes and 18 age-matched controls while silently reading paragraphs of text at font sizes equivalent to 1.0 to $0.2 \log$ MAR acuity. Reading under monocular viewing with amblyopic eye/nondominant eye and nonamblyopic/dominant eye was compared to binocular viewing. Mean reading speed; number, amplitude, and direction of saccades; and fixation duration were calculated for each font size and viewing condition.

REsults. Reading speed was significantly slower in amblyopes compared to controls for all font sizes during monocular reading with the amblyopic eye $(P=0.004)$, but only for smaller font sizes for reading with the nonamblyopic eye $(P=0.045)$ and binocularly $(P=0.038)$. The most significant ocular motor change was that strabismic amblyopes made more saccades per line than controls irrespective of font size and viewing conditions $(P<0.05$ for all $)$. There was no significant difference in saccadic amplitudes and fixation duration was only significantly longer in strabismic amblyopes when reading smaller fonts with the amblyopic eye viewing.

Conclusions. Ocular motor deficits exist in strabismic amblyopes during reading even when reading speeds are normal and when visual acuity is not a limiting factor; that is, when reading larger font sizes with nonamblyopic eye viewing and binocular viewing. This suggests that these abnormalities are not related to crowding.

Keywords: strabismus, amblyopia, reading, visual development, binocular vision

\begin{abstract}
A mblyopia is the most common cause of monocular visual A impairment, and is thought to affect between $2 \%$ and $5 \%$ of the population worldwide. ${ }^{1}$ Because of its high prevalence rate, costs for amblyopia treatment are significant, accounting for approximately $90 \%$ of work in children's eye clinics in the United Kingdom. ${ }^{2}$ The impact of amblyopia on functional vision and quality of life currently are the subject of debate. For example, a large prospective longitudinal study recently concluded that amblyopia or recovered amblyopia does not functionally impact on important "real life" outcomes, such as reading ability. ${ }^{3}$ However, these claims are made despite functional deficits in amblyopia, such as reading having been poorly investigated.

Eye movement recording techniques have been used extensively over several decades of research to investigate ocular motor control during reading, and to test the various reading models that have been proposed. ${ }^{4}$ We recently reported findings of ocular motor reading performance in strabismic amblyopia, and found impairments not only under monocular viewing with the amblyopic eye, but also with the nonamblyopic eye viewing and under binocular viewing. ${ }^{5}$ Reduced reading speeds in strabismic amblyopes were associated with increased number of saccades and the prolonged fixation durations. These findings were observed during text reading of a fixed suprathreshold font size.
\end{abstract}

It has been suggested that reading performance in amblyopia is limited through increased crowding in the central field. ${ }^{6}$ Crowding is a phenomenon in which a letter or symbol that is recognized easily on its own becomes unrecognizable if surrounded by other letters or symbols. Crowding becomes greater for smaller font sizes with more narrow spacing of letters. Another important factor that could influence reading is the existence of central suppression scotomas in amblyopia during binocular viewing. ${ }^{7}$ While the ocular motor performance with reducing print size has been evaluated in individuals with central field loss, either induced artificially or related to eye pathology, ${ }^{8-10}$ to our knowledge it has not been investigated in amblyopia.

In the present study, our aim was to determine the ocular motor patterns associated with reading speed changes as a function of font size. We were interested specifically in whether subclinical ocular motor deficits occur when reading speeds may appear normal.

\section{MeTHODS}

\section{Participants}

A total of 15 participants with strabismic amblyopia (mean age $=44.6$ years, $\mathrm{SD}=8.8$ years; 6 males, 9 females) and 18 healthy 
TABLE 1. Details of the Amblyopic Group

\begin{tabular}{|c|c|c|c|c|c|c|}
\hline \multirow[b]{2}{*}{ ID } & \multirow[b]{2}{*}{ Age } & \multirow[b]{2}{*}{ Sex } & \multirow[b]{2}{*}{ NART } & \multicolumn{3}{|c|}{ Visual Acuity (Viewing Eye) } \\
\hline & & & & Amblyopic & Non-Amblyopic & Binocular \\
\hline \multicolumn{7}{|c|}{ Amblyopes } \\
\hline 1 & 38 & M & 114 & 0.125 & -0.15 & -0.15 \\
\hline 2 & 47 & $\mathrm{~F}$ & 110 & 0.2 & -0.075 & -0.05 \\
\hline 3 & 58 & $\mathrm{~F}$ & 109 & 0.25 & 0 & 0 \\
\hline 4 & 48 & $\mathrm{~F}$ & 102 & 0.475 & 0 & 0 \\
\hline 5 & 58 & $\mathrm{~F}$ & 101 & 0.3 & 0 & 0 \\
\hline 6 & 26 & M & 116 & 0.225 & 0 & 0 \\
\hline 7 & 42 & $\mathrm{~F}$ & 110 & 0.575 & -0.025 & 0 \\
\hline 8 & 40 & M & 107 & 0.175 & 0 & 0 \\
\hline 9 & 45 & $\mathrm{~F}$ & 101 & 0.575 & 0 & 0 \\
\hline 10 & 36 & $\mathrm{~F}$ & 100 & 0.325 & -0.1 & -0.1 \\
\hline 11 & 34 & F & 109 & 0.2 & -0.025 & 0 \\
\hline 12 & 48 & $\mathrm{~F}$ & 122 & 0.475 & -0.075 & -0.075 \\
\hline 13 & 51 & M & 124 & 0.475 & -0.075 & -0.075 \\
\hline 14 & 47 & M & 124 & 0.8 & -0.075 & -0.075 \\
\hline 15 & 51 & M & 114 & 0.2 & -0.05 & -0.05 \\
\hline Mean & 44.6 & & 110.9 & 0.358 & -0.043 & -0.038 \\
\hline SD & 8.8 & & 8.1 & 0.194 & 0.047 & 0.048 \\
\hline
\end{tabular}

NART, National Adult Reading Test.

control volunteers (mean age $=42.0$ years, $S D=9.9$ years; 6 males, 12 females) were recruited to the study (age not significantly different, $t=0.782, P=0.435$ ). The sample size was powered on a previous study based on the number of participants required to show a change in reading speed between amblyopes and controls during binocular viewing $(\alpha$ $=0.01$, power $=80 \%, \delta=7.73$ words $/ \mathrm{min}, \sigma=5.85$ words/ min). Amblyopes were recruited from ocular motility clinics in the Department of Ophthalmology, Leicester Royal Infirmary. The control group was recruited from the nonacademic staff of the University of Leicester/Leicester Royal Infirmary.

Inclusion criteria for the amblyopic group consisted of unilateral amblyopia caused by strabismus, defined as a minimal two logMAR line interocular difference in best corrected distance visual acuity. Exclusion criteria included any neurological or psychiatric disease, or other ocular comorbidity, including latent nystagmus. The details of the tested amblyopes and the control group are shown in Tables 1 and 2. The clinical details of the amblyopes are described in Supplementary Table S1. The study fulfilled the tenets of the Declaration of Helsinki and was approved by the local ethical committee. Written informed consent was obtained from all subjects.

All participants were native English speakers and naïve to eye movement experiments. Each subject was corrected optimally for all clinical vision tests and reading trials. The

TaBLe 2. Details of the Control Group

\begin{tabular}{|c|c|c|c|c|c|c|}
\hline \multirow[b]{2}{*}{ ID } & \multirow[b]{2}{*}{ Age } & \multirow[b]{2}{*}{ Sex } & \multirow[b]{2}{*}{ NART } & \multicolumn{3}{|c|}{ Visual Acuity (Viewing Eye) } \\
\hline & & & & Nondominant & Dominant & Binocular \\
\hline \multicolumn{7}{|l|}{ Controls } \\
\hline 1 & 31 & $\mathrm{~F}$ & 115 & 0 & 0 & 0 \\
\hline 2 & 54 & $\mathrm{~F}$ & 108 & -0.075 & -0.1 & -0.1 \\
\hline 3 & 32 & $\mathrm{~F}$ & 115 & 0 & 0 & 0 \\
\hline 4 & 27 & $\mathrm{~F}$ & 103 & 0.025 & -0.05 & -0.05 \\
\hline 5 & 46 & M & 117 & -0.05 & -0.05 & -0.05 \\
\hline 6 & 49 & $\mathrm{~F}$ & 103 & 0 & -0.025 & 0 \\
\hline 7 & 43 & M & 100 & -0.5 & -0.5 & -0.5 \\
\hline 8 & 58 & $\mathrm{~F}$ & 107 & 0 & 0 & 0 \\
\hline 9 & 52 & F & 112 & -0.025 & 0 & 0 \\
\hline 10 & 45 & F & 114 & -0.025 & -0.025 & -0.025 \\
\hline 11 & 34 & $\mathrm{~F}$ & 112 & 0 & 0 & -0.025 \\
\hline 12 & 44 & $\mathrm{~F}$ & 121 & 0 & 0 & 0 \\
\hline 13 & 24 & M & 105 & -0.025 & -0.05 & -0.05 \\
\hline 14 & 50 & M & 114 & -0.05 & -0.05 & -0.05 \\
\hline 15 & 50 & M & 105 & -0.025 & -0.025 & -0.025 \\
\hline 16 & 36 & $\mathrm{~F}$ & 111 & 0 & -0.025 & -0.025 \\
\hline 17 & 47 & $\mathrm{~F}$ & 117 & 0 & 0 & 0 \\
\hline 18 & 34 & M & 115 & -0.025 & -0.025 & 0 \\
\hline Mean & 42 & & 110.8 & -0.043 & -0.051 & -0.050 \\
\hline SD & 9.9 & & 5.9 & 0.117 & 0.115 & 0.116 \\
\hline
\end{tabular}




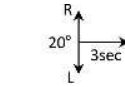

Viewing Eye $\Rightarrow$ Amblyopic

Amblyopic Eye

1.0
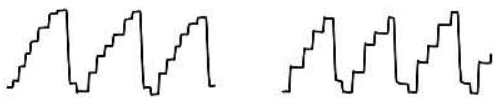

0.8
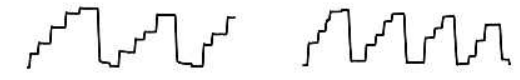

0.7

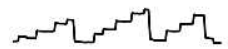

0.6
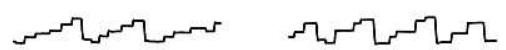

0.5

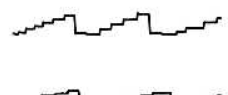

0.4

0.3

0.2
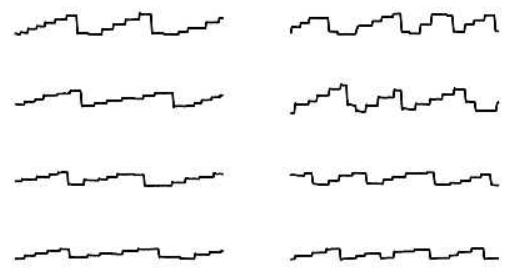

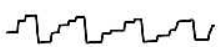

Amblyope

Non-amblyopic Eye
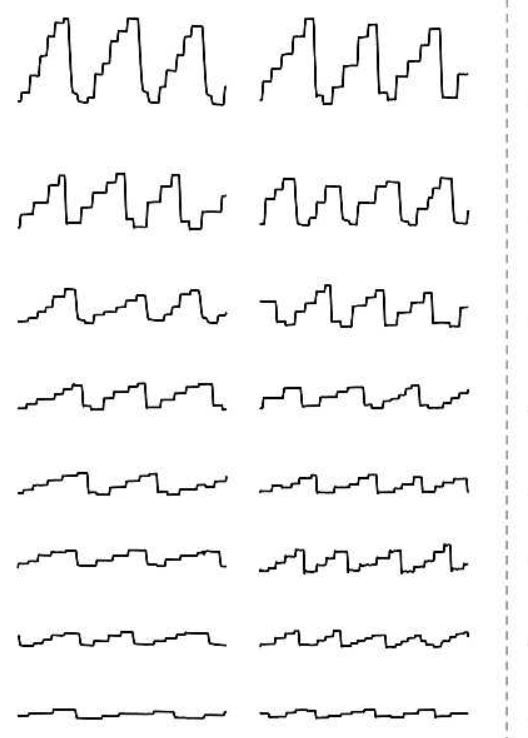

Control

Binocular
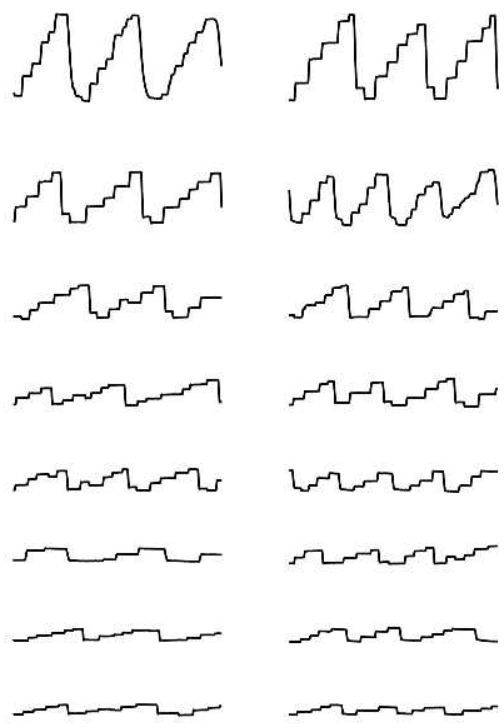

FiguRE 1. Original recordings of an amblyope and control under monocular viewing with either eye and under binocular viewing. In the selected time period of 10 seconds, less lines of text were read during monocular viewing with either eye and binocular viewing of the amblyopic subject compared to the normal control. Amblyopes also tended to make more saccades and fixations compared to controls for all font sizes and viewing conditions.

National Adult Reading Test (NART) was used to test educational intelligence and involves testing the correct pronunciation of a series of single words that all are "irregular" with respect to the common rules of pronunciation. ${ }^{10}$ Both groups were matched according to NART score $(t=0.007, P=$ 0.971 ; Tables 1, 2).

\section{Clinical Assessments}

A full ophthalmic examination was performed on all participants. This included best corrected distance visual acuity measured using a logMAR crowded acuity test (ETDRS), binocular function tested using the Bagolini striated glasses, stereopsis/stereo acuity tested with the TNO test, an ocular motility examination, cover/uncover and alternate cover tests, slit-lamp examination, and direct ophthalmoscopy.

Of the amblyopic volunteers, 10 showed total suppression with the Bagolini test and five amblyopic volunteers showed central suppression only (Table 1). None of the amblyopic volunteers demonstrated stereovision. The healthy controls showed no suppression and their mean stereo acuity was 60 $\min$ arc

\section{Reading Paradigms}

Participants were required to read paragraphs of text that were selected excerpts taken from the "Oxford First Encyclopedia" (Oxford University Press, Oxford, UK) so that there was no difficulty with comprehension of the text. ${ }^{11}$ Each paragraph was designed to give the same layout consisting of approximately the same number of characters with spaces (mean characters with spaces $\pm \mathrm{SD}=300.3 \pm 8.3$, mean number of words $=60.5 \pm 3.2$, mean words/line $=5.4 \pm 0.3$ ).

The paragraphs were generated as Microsoft PowerPoint (Microsoft Corporation, Redmond, WA) slides using font sizes selected to correspond to the following logMAR equivalent sizes: $1.0,0.8,0.7,0.6,0.5,0.4,0.3$, and $0.2 \log$ MAR optotype equivalents. Three paragraphs were created for each font size, of which one was chosen using a random number generator created using a Microsoft Excel Template. The logMAR equivalent print sizes were estimated from the height of a lowercase "x." The corresponding logMAR size was based on the following equation as described in the MNREAD acuity charts $^{12}$ :

$$
\begin{gathered}
\log \text { MAR equivalent size }= \\
\log _{10}([\text { angle subtended by } x-\text { beight }] /[5 \text { arc } \mathrm{min}])
\end{gathered}
$$

Left justified text without splitting of words was presented using a monospaced font (Courier New font) and the text was centered on the screen.

The text was presented as black letters (luminance $=0.45$ $\mathrm{cd} / \mathrm{m}^{2}$ ) on a white background (luminance $=12.0 \mathrm{~cd} / \mathrm{m}^{2}$, letter contrast $=96.25 \%$ ) using a video projector (Epson EMP-703, $1024 \times 768$ resolution; Epson, Tokyo, Japan) projecting onto a rear projection screen $(1.75 \mathrm{~m}$ width and $1.17 \mathrm{~m}$ height). To avoid pixilation effects, two throw distances were used for the projector using a smaller distance for the smaller print sizes, with luminances of the fonts and background matched using the projector settings. The order of presentation of fonts was randomized for each projector throw distance using the random number generator in the Microsoft Excel Template mentioned above (smaller throw distance for 0.7, 0.6, 0.5, 0.4, 0.3 , and $0.2 \log$ MAR font sizes, and longer throw distance for 1.0 and $0.8 \log$ MAR font sizes). Participants were seated at a distance of $2 \mathrm{~m}$ in front of the stimulus display screen with the head stabilized using a forehead and chin rest. Primary position of gaze corresponded to the screen center.

Participants were instructed to read the text silently. Silent reading was used as the chin rest limits jaw movements and 
A. Amblyopic eye / non-dominant eye viewing

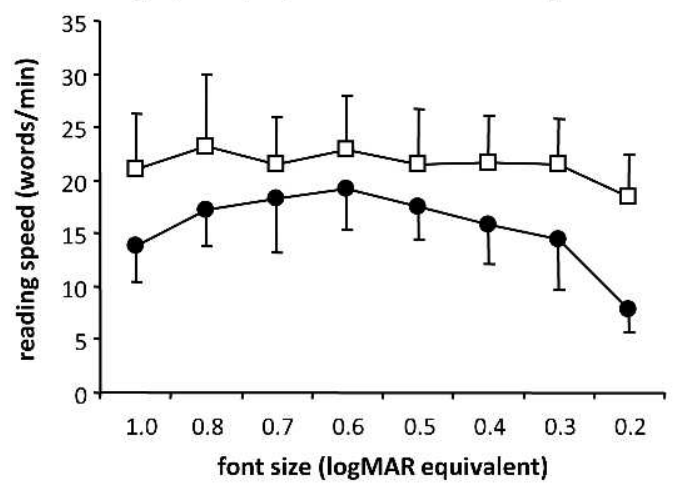

B. Non-amblyopic eye / dominant eye viewing
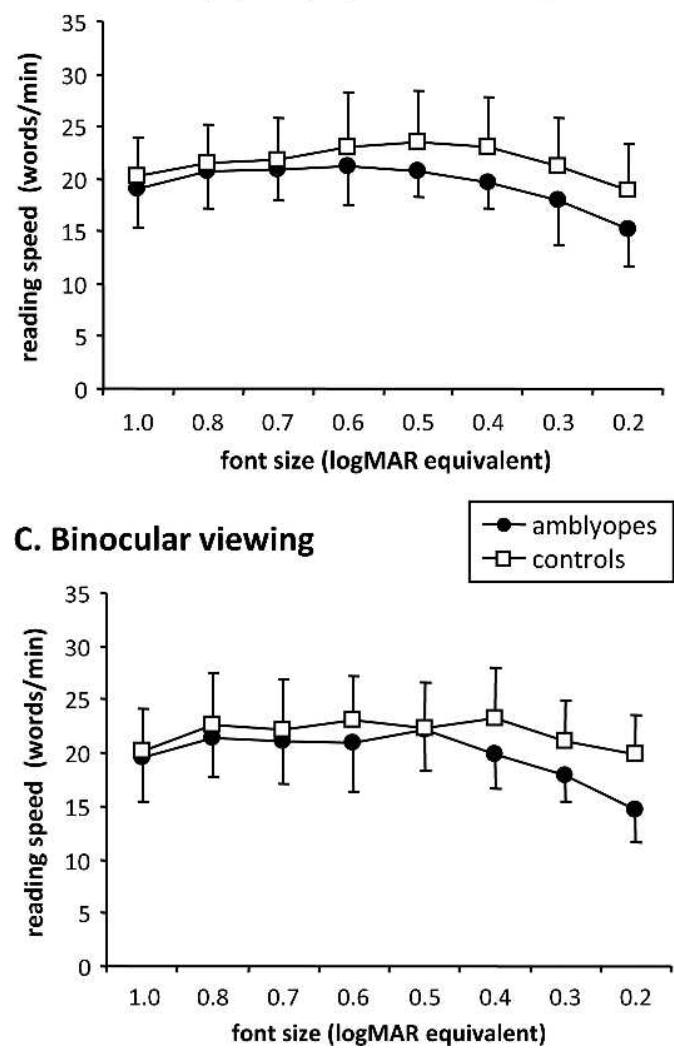

Figure 2. Mean and standard deviation (error bars) of reading speed with reducing font size for all three viewing conditions in amblyopes (filled circles) and controls (open squares).

speaking can introduce artifacts in eye movement data by causing vibration of the head mounted eye tracker. After reading each paragraph, participants were presented with a single word and asked to decide whether it was relevant to the previously read text, with 18 questions in total. All subjects answered the questions correctly, demonstrating accurate comprehension. Binocular viewing, amblyopic eye viewing, and dominant eye viewing were performed in random order. During monocular reading, the contralateral eye was occluded using a black opaque occluder. The test duration was approximately 1 hour.

\section{Eye Movement Recordings}

An infrared video based pupil-tracker (EyeLink; SensoMotoric Instruments $\mathrm{GmbH}$, Berlin, Germany) with a sample rate of
$250 \mathrm{~Hz}$ (spatial resolution $=0.005^{\circ}$, spatial accuracy $=0.5^{\circ}$, noise level $<0.01^{\circ}$ RMS) was used to record horizontal and vertical eye movements. Data from both eyes were recorded, but only data from the viewing eye were analyzed (dominant eye was used for binocular viewing). The system also recorded head movement and, hence, gave an output of gaze angle. The system calibration was performed monocularly with a series of nine fixation points followed by a validation routine. Saccades were detected using an automatic saccadic detection algorithm based on a velocity threshold of $35^{\circ} / \mathrm{s}$ and an acceleration threshold of $9500^{\circ} / \mathrm{s}^{2}$.

\section{Data Analysis}

Eye movement data files were converted to Spike2 software (Cambridge Electronic Design Ltd., Cambridge, UK) system files for subsequent analysis. Reading speeds (in words/ minutes) were calculated from the words for each paragraph of text divided by the time taken to read the paragraph. Semiautomated custom-written Spike2 scripts were used to calculate the other parameters. Cursors were placed from the middle of the first and last fixations of each line read, and the following parameters were calculated by the script: total number of saccades per line, number of forward (progressive) saccades per line, no of regressive (backward) saccades per line, amplitude of forward saccades (in degrees), and fixation duration (in $\mathrm{msec}$ ). Means were calculated for all parameters for each subject.

\section{Statistical Analysis}

Differences between amblyopes and controls were assessed using repeated measures ANOVAs including group as a factor, and investigating the interaction between group and rate of change with font size. Visual acuity (under the same viewing condition), age, sex, and NART score also were explored as possible factors that could influence each outcome parameter. IBM SPSS v. 20.0 was used to perform the analysis (IBM Corporation, Armonk, NY). The following comparisons were made: monocular reading with the amblyopic eye of the amblyopes and the nondominant eye of the controls, monocular reading with the nonamblyopic eye of the amblyopes and the dominant eye of the controls, and binocular reading. During binocular viewing, eye movement recordings from the nonamblyopic eye of the amblyopes and the dominant eye of the controls were selected for the analysis. The dominant eye was determined as the eye the participants chose spontaneously when looking through a pinhole in a paper (always the nonamblyopic eye in amblyopes).

When evaluating monocular reading with the amblyopic eye, only the 10 amblyopes who could read down to 0.4 logMAR were included in the analysis $(n=6$ reached 0.2 logMAR equivalent, 9 reached 0.3 logMAR, 10 reached 0.4 logMAR, 11 reached $0.7 \log$ MAR, and 13 reached $1.0 \log M A R)$. For the statistical comparisons, only font sizes from 1.0 to 0.3 were included in the statistical model. The single missing value for one subject reading only to $0.4 \log$ MAR was estimated using an averaging method. For all other conditions (all three viewing conditions for controls, and binocular viewing or nonamblyopic eye viewing in amblyopes) all font sizes presented were read successfully by all participants analyzed.

\section{Results}

Original eye movement recordings of an amblyope and control are illustrated in Figure 1 for the different font sizes for each of the viewing conditions. A clear difference in reading speed 


\section{A. Total Number of Saccades}

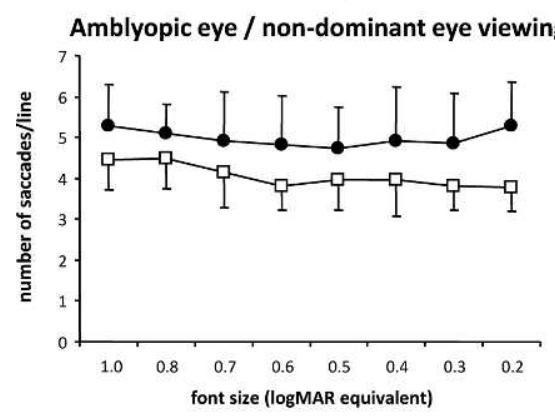

Non-amblyopic eye / dominant eye viewing

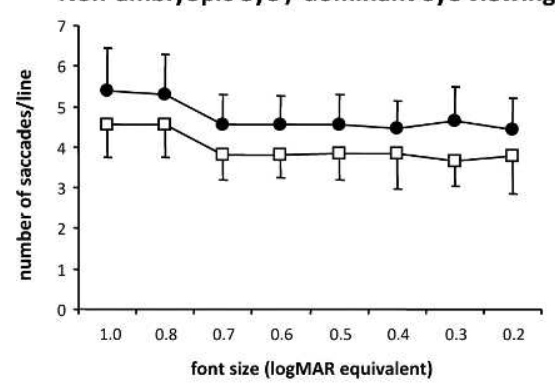

Binocular viewing

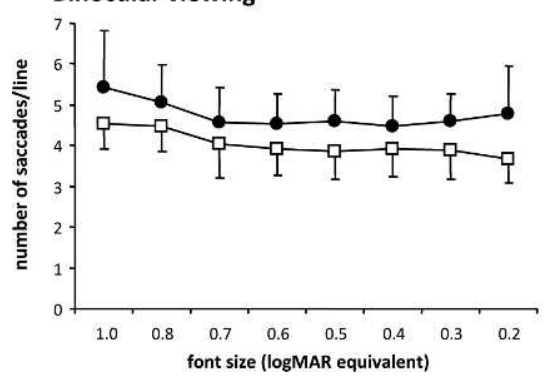

B. Number of Forward Saccades

\section{Number of Regressive Saccades}
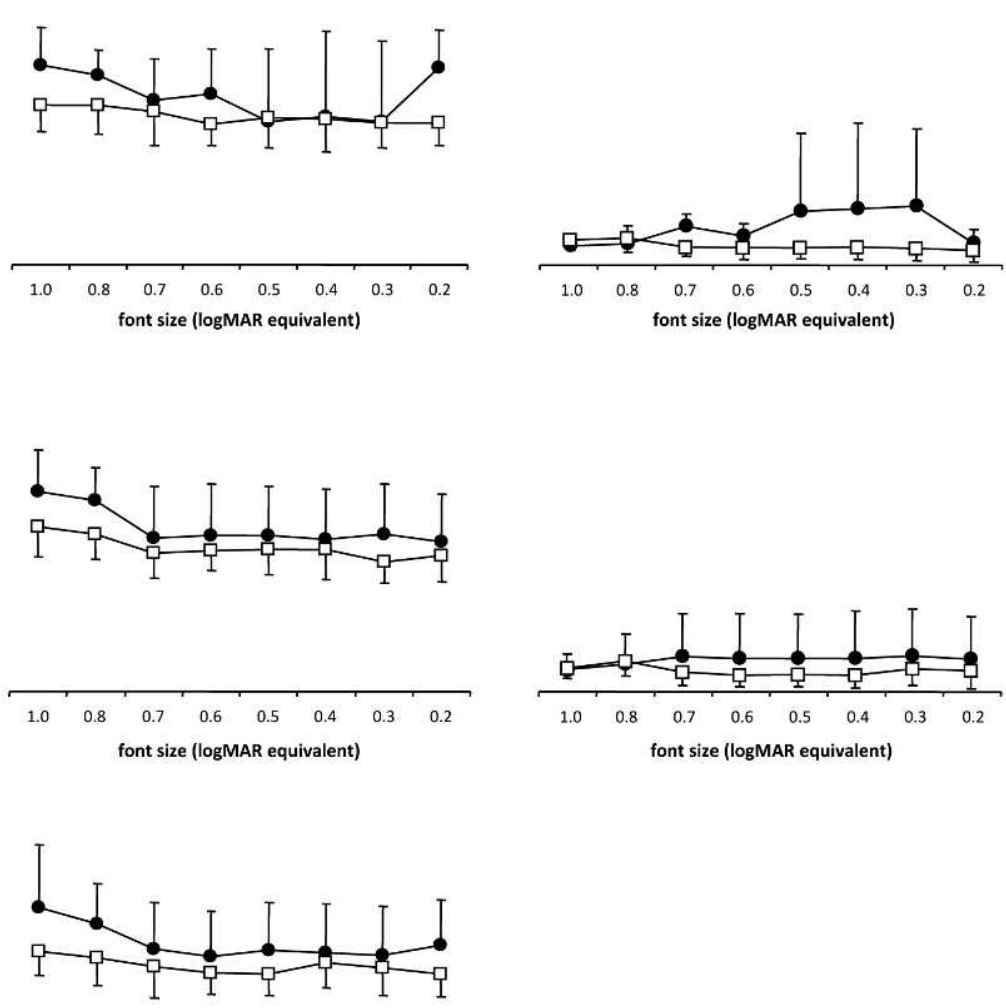

\begin{tabular}{llllllll}
\hline 1.0 & 0.8 & 0.7 & 0.6 & 0.5 & 0.4 & 0.3 & 0.2 \\
font size (logMAR equivalent)
\end{tabular}

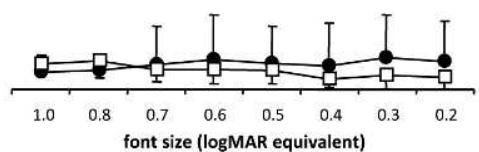

Figure 3. Change in (A) total number of saccades per line, (B) number of forward saccades per line, and (C) number of regressive saccades per line for all three viewing conditions in amblyopes (filled circles) and controls (open squares).

between the two subjects is evident from the number of lines read in the 10-second time interval of data shown on the Figure. On average, three lines of text were read by the amblyope in each viewing condition for each of the tested font sizes, whereas four lines were read by the control in the same period of time. For all three viewing conditions, amblyopes tended to make more saccades and fixations than control participants, regardless of the font size.

\section{Reading Speeds}

Means (with standard deviations) of the reading speed are illustrated in Figure 2 for the amblyopes and the controls under all three viewing conditions.

Reading rate curves could be modeled approximately with a quadratic curve. In amblyopia, a shift downwards across the whole curve was observed when the amblyopic eye was viewing. During nonamblyopic/dominant eye viewing and binocular viewing, the differences were mainly apparent for smaller fonts. On the whole, reading speed was significantly impaired in the amblyopes compared to controls for all three viewing conditions $(F=10.681, P=0.004$ for the amblyopic eye versus nondominant eye viewing; $F=4.367, P=0.045$ for nonamblyopic eye versus dominant eye viewing; and $F=$ 4.722, $P=0.038$ for binocular viewing, Table 3 ).
The rate of change in reading speed with print size was not significantly different between the two groups (Wilks' $\lambda=$ $0.514, P=0.119$ for amblyopic eye versus nondominant eye viewing; Wilks' $\lambda=0.732, P=0.314$ for nonamblyopic eye versus dominant eye viewing; and Wilks' $\lambda=0.642, P=0.112$ or binocular viewing) although reading speed changed significantly with the print sizes for each condition (Wilks' $\lambda=0.179, P<0.0001$ for amblyopic eye/nondominant eye viewing; Wilks' $\lambda=0.155, P<0.0001$ for nonamblyopic eye/ dominant eye viewing; Wilks' $\lambda=0.242, P<0.0001$ for binocular viewing).

\section{Ocular Motor Parameters}

Means and standard deviations (error bars) of the ocular motor parameters with reducing font size in amblyopes and controls are shown in Figure 3 for the number of saccades per line (broken down into forward and regressive saccades), and in Figure 4 for amplitude of forward saccades and fixation durations (Figs. 4A, 4B, respectively). The results of the repeated measures ANOVAs statistical analysis are shown in Table 3.

The statistical analysis revealed that the most significant ocular motor changes underlying the reduction in reading speeds in the three viewing conditions were due to the increased total number of saccades made per line by 


\section{A. Amplitude of Forward Saccades}

Amblyopic eye / non-dominant eye viewing

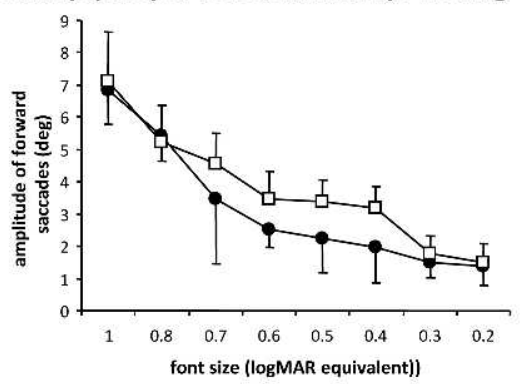

Non-amblyopic eye / dominant eye viewing
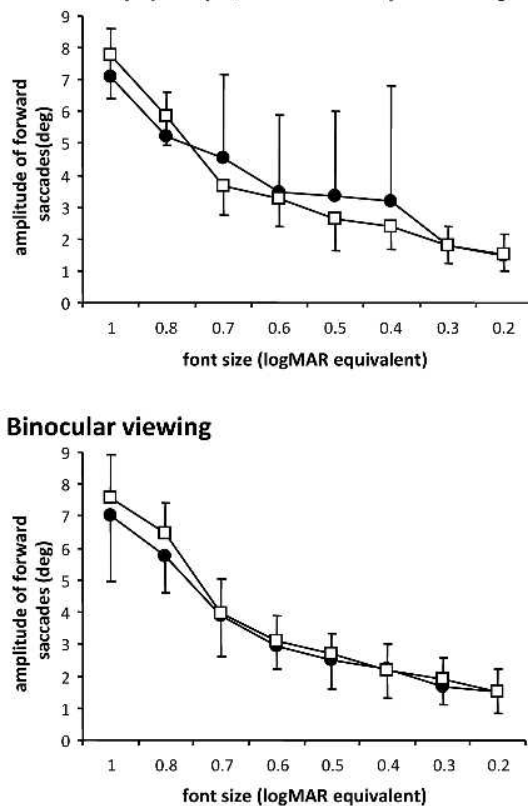

\section{B. Fixation Duration}
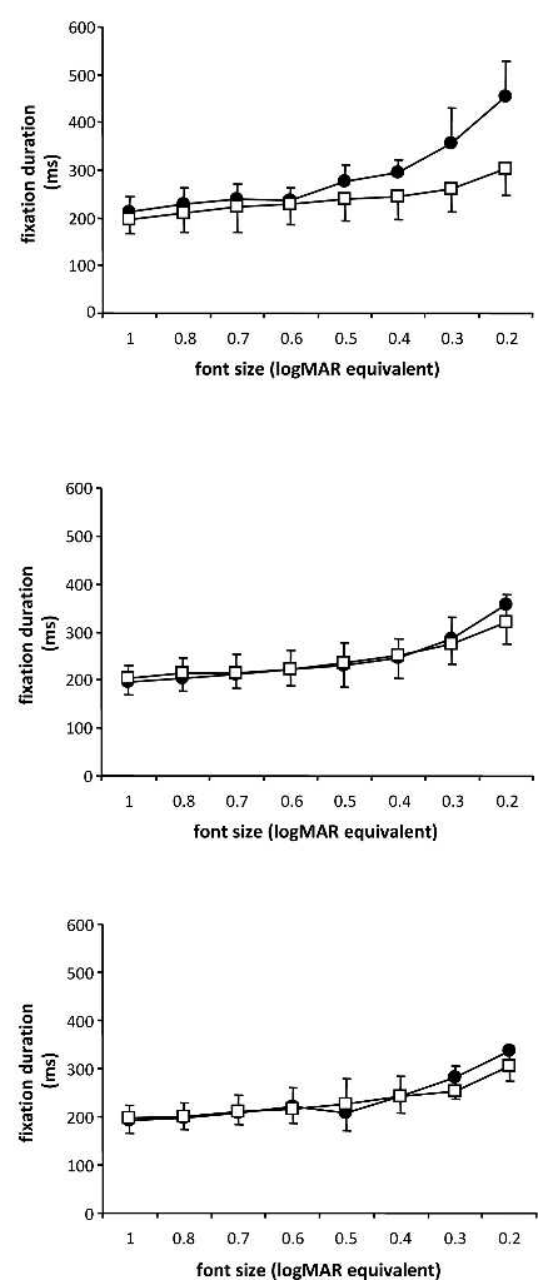

Figune 4. Change in (A) amplitude of forward saccades and (B) fixation durations for all three viewing conditions in amblyopes (filled circles) and controls (open squares).

amblyopes during all three conditions (Fig. 3, Table 3). The significant differences were more apparent during binocular viewing and nonamblyopic/dominant eye viewing $(P<0.0001$ for both conditions) than during amblyopic/nondominant eye viewing $(P=0.02)$ despite amblyopes having better visual acuity during the former two conditions. Also, the differences were apparent for all font sizes in all conditions in contrast to reading speed, where the differences were apparent only for smaller font sizes. The total number of saccades per line did not show a significant change with font size for all three viewing conditions $(P>0.05)$

The standard deviations of total number of saccades per line at each font size for amblyopes tended to be less than that for number of forward and regressive saccades per line. This was due to different approaches used by amblyopes in the degree to which they read more carefully by reread words or using more fixations (Fig. 3). The different strategies used led to only borderline significant differences between amblyopes and controls being evident for the number of forward saccades made per line, and no differences for the number of regressive saccades made per line.

There were no significant difference between amblyopes and controls for amplitude of forward saccades and fixation durations (Fig. 4) except for when the amblyopic eye/ nondominant eye was viewing where longer fixations were made by amblyopes, with the differences becoming greater for smaller font sizes (Fig. 4B, Table 3). Amplitude of forward saccades and fixation durations showed highly significant changes with font size ( $P<0.0001$ for all conditions), although the patterns were contrasting. Saccadic amplitudes of forward saccades were significantly less for smaller font sizes and fixation durations were significantly greater.

There were no significant differences in the rate of change of any parameter with font size between amblyopes and controls for any comparison (as indicated by the group $\times$ rate of change comparisons in Table 3).

Visual acuity (under the same viewing condition), age, NART, and sex were all explored as possible factors that could significantly explain the variance of the reading speed or of each ocular motor outcome measure, but all were found to be nonsignificant $(P>0.05)$

\section{Discussion}

\section{Reading Deficits in Amblyopes}

We used a paradigm of paragraph reading using texts of reducing font size to investigate possible crowding effects 
Table 3. Statistical Comparisons Made Using Repeated Measures ANOVAs Where the F-Statistic Is Shown for Comparison of the Two Groups (Amblyopes and Controls)

\begin{tabular}{|c|c|c|c|c|c|c|}
\hline \multirow[b]{3}{*}{ Amblyopes Controls } & \multicolumn{6}{|c|}{ Viewing Eye } \\
\hline & \multicolumn{2}{|c|}{$\begin{array}{c}\text { Amblyopic Eye } \\
\text { Nondominant Eye }\end{array}$} & \multicolumn{2}{|c|}{$\begin{array}{c}\text { Nonamblyopic Eye } \\
\text { Dominant Eye }\end{array}$} & \multicolumn{2}{|c|}{$\begin{array}{l}\text { Binocular } \\
\text { Binocular }\end{array}$} \\
\hline & F/Wilks' $\lambda$ & $\boldsymbol{P}$ & F/Wilks' $\lambda$ & $\boldsymbol{P}$ & F/Wilks' $\lambda$ & $\boldsymbol{P}$ \\
\hline \multicolumn{7}{|l|}{ Reading speed, words/min } \\
\hline Group & 10.649 & 0.003 & 4.367 & 0.045 & 4.722 & 0.038 \\
\hline Rate of change & 0.379 & 0.002 & 0.155 & $<0.0001$ & 0.242 & $<0.0001$ \\
\hline Group $\times$ rate of change & 0.599 & 0.082 & 0.732 & 0.314 & 0.642 & 0.112 \\
\hline \multicolumn{7}{|l|}{ Total number of saccades/line } \\
\hline Group & 10.494 & 0.003 & 17.797 & $<0.0001$ & 15.869 & $<0.0001$ \\
\hline Rate of change & 0.687 & 0.222 & 0.693 & 0.210 & 0.616 & 0.078 \\
\hline Group $\times$ rate of change & 0.846 & 0.723 & 0.725 & 0.293 & 0.725 & 0.293 \\
\hline \multicolumn{7}{|c|}{ Number of forward saccades/line } \\
\hline Group & 2.890 & 0.102 & 4.177 & 0.050 & 6.271 & 0.058 \\
\hline Rate of change & 0.366 & 0.001 & 0.547 & 0.026 & 0.522 & 0.017 \\
\hline Group $\times$ rate of change & 0.664 & 0.175 & 0.649 & 0.122 & 0.773 & 0.450 \\
\hline \multicolumn{7}{|l|}{$N$ of reverse saccades/line } \\
\hline Group & 1.559 & 0.223 & 1.462 & 0.236 & 0.646 & 0.428 \\
\hline Rate of change & 0.730 & 0.331 & 0.774 & 0.456 & 0.502 & 0.051 \\
\hline Group $\times$ rate of change & 0.758 & 0.415 & 0.879 & 0.845 & 0.759 & 0.400 \\
\hline \multicolumn{7}{|c|}{ Amplitude of forward saccades, deg } \\
\hline Group & 4.103 & 0.054 & 0.16 & 0.692 & 1.345 & 0.255 \\
\hline Rate of change & 0.052 & $<0.0001$ & 0.042 & $<0.0001$ & 0.037 & $<0.0001$ \\
\hline Group $\times$ rate of change & 0.723 & 0.311 & 0.804 & 0.568 & 0.86 & 0.781 \\
\hline \multicolumn{7}{|l|}{ Fixation durations, msec } \\
\hline Group & 6.823 & 0.015 & 0.031 & 0.861 & 0.257 & 0.616 \\
\hline Rate of change & 0.215 & $<0.0001$ & 0.135 & $<0.0001$ & 0.104 & $<0.0001$ \\
\hline Group $\times$ rate & 0.572 & 0.058 & 0.856 & 0.798 & 0.686 & 0.192 \\
\hline
\end{tabular}

Wilk's $\lambda$ statistics are shown for the rate of change of each parameter with reducing font size and for the comparison as to whether this is different in the two groups (i.e. group $\times$ rate of change).

associated with reading in strabismic amblyopia. We also have used eye movement recording methods to investigate underlying ocular motor deficits in reading in strabismic amblyopia. During reading with the amblyopic eye, strabismic amblyopes demonstrated lower reading speeds for all font sizes, with the differences becoming greater for smaller font sizes. During monocular viewing with the nonamblyopic eye and binocular viewing, reading speeds were relatively normal in strabismic amblyopes for larger font sizes, but significant impairments existed when reading smaller font sizes. We found that significantly more saccades were made per line by amblyopes regardless of the viewing condition or font size and even when reading speeds were relatively normal. Fixation durations became significantly longer when strabismic amblyopes read smaller fonts, but only when the amblyopic eye was viewing.

\section{Change in Reading Speed With Font Size}

The classic reading rate curve with changing font size consisting of a "cliff and wide plateau" has been described by Legge et al. ${ }^{13}$ using the rapid serial presentation of text (RSVP) technique in individuals with normal central vision. The reading speed increases with increasing print size up to a critical print size, beyond which reading speed remains at a plateau level. In our investigation, the reading speed changes across the print sizes approximated to a quadratic curve in the amblyopes and controls due the reading speed falling off slightly at the largest font size.

Reading speed as a function of font size has been plotted previously in a group of 20 children with microstrabismus in comparison to 20 controls by Stifter et al. ${ }^{14}$ Similar reading speed curves were observed, although Stifter et al. ${ }^{14}$ did not observe any significant differences in reading speed when the nonamblyopic eye was viewing in contrast with our findings. However, much smaller paragraphs are found in the Radner reading chart used by Stifter et al. ${ }^{14}$ to evaluate reading performance compared to our paradigm. Also, the use of microstrabismic children rather than strabismic adults is likely to lead to differences in reading performance. The nonamblyopic eye of strabismic amblyopes has been shown to exhibit sensory and ocular motor abnormalities, such as unsteady and eccentric fixations, ${ }^{15}$ reduced contrast sensitivity $^{16,17}$ and Vernier acuity, ${ }^{18}$ and increased crowding. ${ }^{6,19}$

The most obvious mechanism leading to deterioration in reading speed with reducing font size is the phenomenon of crowding. Levi et al. ${ }^{6}$ have suggested that the amblyopic deficits observed during reading mainly are due to the increased crowding effect in amblyopic fovea, and speculate that reading rates in amblyopia can be predicted using the "uncrowded span theory." The idea behind this theory is that maximum reading rates with the amblyopic fovea can equal maximum reading rates with normal fovea, after accounting for the increased critical spacing needed in the amblyopic fovea. Reading rates with the amblyopic periphery, however, were shown to be similar to the normal periphery.

In contrast with this theory, Chung et al. ${ }^{20}$ investigated the effect of print size in normal central and peripheral vision using the RSVP technique, and concluded that, although the rate of change of reading speed remained invariant in central and peripheral vision, maximum reading speeds still were lower in peripheral vision compared to central vision. They 
suggest that unique characteristics of the normal fovea are required to accomplish satisfactory reading rates.

One key difference between these two studies and our investigation is that they both used the RSVP technique, eliminating the need to make eye movements to read. In this study, we showed that when strabismic amblyopes make eye movements to read they invariably make more saccades regardless of the viewing condition (binocular or monocular viewing with either eye) or the font size being read. Indeed, differences are even more significant during monocular viewing with the nonamblyopic eye or binocularly, although reading rates are relatively normal for larger font sizes and crowding effects are no longer a limiting factor. This also implies that there are factors that impair reading in strabismic amblyopia that are independent of crowding, which lead to subclinical ocular motor reading impairments when reading speeds appears normal. Future studies could tease apart the limitations imposed by crowding effects in amblyopia during paragraph reading by manipulating font, word, and line spacing.

Another possible factor that could influence reading is suppression scotomas. ${ }^{7}$ We observed similar patterns when strabismic amblyopes read with either the nonamblyopic eye viewing or during binocular viewing in that reading speed impairments are observed only for small font sizes. This suggested that reduction in reading speed for smaller font sizes in these two conditions is likely to be due to effects other than suppression scotomas, which would not be present under monocular viewing.

\section{Ocular Motor Patterns Observed During Reading}

The most consistent ocular motor change we observed during reading in strabismic amblyopes was the increase in the number of saccades (and, hence, fixations) made. The increased number of saccades was due to increased regressions to reread words in certain individuals, but not others, which suggested different strategies were being used by different strabismic amblyopes when reading. Regressive saccades are associated with problems with linguistic processing or ocular motor errors. Our participants were matched according to the NART IQ test to minimize intellectual differences between the groups. Therefore, difficulties in determining where to direct the subsequent saccades could explain the higher regressive saccades rate in some individuals.

In a recent study, Lions et al. ${ }^{21}$ have shown that saccadic amplitudes are no different in strabismic children, in agreement with the findings of this study and also our previous study. However, they also found poorer binocular coordination during reading in strabismic children due to increased saccadic disconjugacy. This could contribute to impairments we observed in strabismic amblyopes when reading under binocular viewing conditions, but it is unlikely to affect reading performance under monocular viewing. Lions et al. ${ }^{21}$ also observed greater postsaccadic drift in strabismic children. A recent study by Subramanian et al. ${ }^{22}$ also has observed a high level of fixation instability in strabismic children, which contributes to reduced visual acuity in amblyopia.

Lions et al. ${ }^{21}$ recently have suggested that the duration of fixations in strabismic amblyopes depends more on the strabismus than on abnormal visual input, since children with and without binocular function show prolonged fixation durations. However, we only observed prolonged fixation durations during monocular viewing of text with the amblyopic eye, which suggests that this is not an effect of binocularity. Also, we observed that the increase in mean fixation duration when reading with the amblyopic eye was apparent particularly when reading smaller fonts. This suggests that this could be an effect of increased crowding where reading with an amblyopic fovea leads to increased processing times.

In summary, we found that reading speeds under binocular viewing become increasingly abnormal with reducing font size, despite binocular best corrected visual acuities being relatively normal. These could have important significance in an educational and vocational context. We also found that subclinical ocular motor deficits exist during reading in strabismic amblyopes irrespective of font size or viewing condition, even when reading speeds can appear normal. These findings support the use of the clinical reading tests to evaluate the outcomes of amblyopia treatment and that additional assistance or reeducation may be necessary where significant reading deficits exist.

\section{Acknowledgments}

Supported by Ulverscroft Foundation.

Disclosure: E. Kanonidou, None; I. Gottlob, None; F.A. Proudlock, None

\section{References}

1. Simons K. Amblyopia characterization, treatment, and prophylaxis. Surv Opbthalmol. 2005;50:123-166.

2. Stewart CE, Moseley MJ, Stephens DA, Fielder AR. Treatment dose-response in amblyopia therapy: the Monitored Occlusion Treatment of Amblyopia Study (MOTAS). Invest Ophthalmol Vis Sci. 2004;45:3048-3054

3. Wilson GA, Welch D. Does amblyopia have a functional impact? Findings from the Dunedin Multidisciplinary Health and Development Study. Clin Exp Ophthalmol. 2013;41:127134.

4. Rayner K. Eye movements in reading and information processing: 20 years of research. Psychol Bull. 1998;124: 372-422.

5. Kanonidou E, Proudlock FA, Gottlob I. Reading strategies in mild to moderate strabismic amblyopia: an eye movement investigation. Invest Ophthalmol Vis Sci. 2010;51:3502-3508.

6. Levi DM, Song S, Pelli DG. Amblyopic reading is crowded. $J$ Vis. 2007;21:1-17.

7. Harrad R, Sengpiel F, Blakemore C. Physiology of suppression in strabismic amblyopia. Br J Opbthalmol. 1996;80:373-377.

8. Bullimore MA, Bailey IL. Reading and eye movements in agerelated maculopathy. Optom Vis Sci. 1995;72:125-138.

9. Crossland MD, Culham LE, Rubin GS. Fixation stability and reading speed in patients with newly developed macular disease. Opbthalmic Pbysiol Opt. 2004;24:327-333.

10. McMahon TT, Hansen M, Viana M. Fixation characteristics in macular disease. Relationship between saccadic frequency, sequencing, and reading rate. Invest Opbthalmol Vis Sci. 1991;32:567-574.

11. Langley A. Oxford First Encyclopedia. New Ed. Oxford, UK: Oxford University Press; 2005.

12. Legge GE, Ross JA, Luebker A, LaMay JM. Psychophysics of reading. VIII. The Minnesota Low-Vision Reading Test. Optom Vis Sci. 1989;66:843-853.

13. Legge GE, Pelli DG, Rubin GS, Schleske MM. Psychophysics of reading-I. Normal vision. Vision Res. 1985;25:239-252.

14. Stifter E, Burggasser G, Hirmann E, Thaler A, Radner W. Monocular and binocular reading performance in children with microstrabismic amblyopia. Br J Opbthalmol. 2005;89: 1324-1329.

15. Kandel GL, Grattan PE, Bedell HE. Are the dominant eyes of amblyopes normal? Am J Optom Pbysiol Optics. 1980;57:1-6. 
16. Reed MJ, Steeves JK, Steinbach MJ, Kraft S, Gallie B. Contrast letter thresholds in the nonaffected eye of strabismic and unilateral eye enucleated subjects. Vision Res. 1996;36:30113018.

17. Wali N, Leguire LE, Rogers GL, Bremer DL. CSF interocular interactions in childhood ambylopia. Optom Vis Sci. 1991;68: 81-87.

18. Levi DM, Klein SA. Vernier acuity, crowding and amblyopia. Vision Res. 1985;25:979-991.

19. Levi DM. Crowding-an essential bottleneck for object recognition: a mini-review. Vision Res. 2008;48:635-654.
20. Chung ST, Mansfield JS, Legge GE. Psychophysics of reading. XVIII. The effect of print size on reading speed in normal peripheral vision. Vision Res. 1998;38:2949-2962.

21. Lions C, Bui-Quoc E, Seassau M, Bucci MP. Binocular coordination of saccades during reading in strabismic children. Invest Ophthalmol Vis Sci. 2013;54:620-628.

22. Subramanian V, Jost RM, Birch EE. A quantitative study of fixation stability in amblyopia. Invest Ophthalmol Vis Sci. 2013;54:1998-2003. 